\title{
CLEANING OF BEYŞEHİR (BAYAVŞAR) COAL IN TURKEY WITH HYDROPHOBIC FLOCCULATION USING WASTE MOTOR OIL
}

\author{
Tevfik Agacayak $^{\mathrm{a}^{*}}$, Osman Agca \\ ${ }^{a}$ Department of Mining Engineering, Konya Technical University, Konya, \\ Turkey \\ ${ }^{b}$ Institute of Graduate Studies, Department of Mining Engineering, Konya \\ Technical University, Konya, Turkey
}

\begin{abstract}
In this study, the hydrophobic flocculation behavior of lignite coal obtained from Beyşehir region in Turkey and the effect of some parameters were investigated. These parameters were selected as $\mathrm{pH}$, amount of dispersant, amount of binding liquid, flock growth time, stirring speed, flocculation time and solid ratio. The ash content (ash, \%) and combustible recovery (CR, \%) of the flocks obtained as a result of the experiments were determined. As a result of the studies, the optimum $\mathrm{pH}$ value (3), amount of sodium silicate $(1 \mathrm{~mL})$, amount of waste motor oil (3 $\mathrm{mL})$, flock growth time $(1 \mathrm{~min})$, stirring speed $(1250 \mathrm{rpm})$, flocculation time ( $2 \mathrm{~min}$ ) and solid ratio (5 g) were determined. The hydrophobicity of fine coal grains was increased by using waste motor oil. According to the hydrophobic flocculation results of coal grains, flocks with $17.03 \%$ ash content and $99.06 \%$ combustion recovery were obtained. While the contact angle of the original coal was $44^{\circ}$, it was observed that the contact angle of the obtained flocks reached $117^{\circ}$. It was determined from experiments that the surfaces of the coal grains have a very high hydrophobicity. As a result, clean coal with a reduced ash content of $53.22 \%$ was obtained.
\end{abstract}

Keywords: Lignite, hydrophobic flocculation, combustion recovery, waste motor oil, contact angle, Beyşehir, Turkey.

\section{Introduction}

It is known that there are many countries that provide a significant part of their energy needs from coal. Especially, with the development of

\footnotetext{
* Tevfik Agacayak, e-mail: tagacayak@ktun.edu.tr
} 
technology, more than 1/4 of its primary energy needs are supplied from coal. ${ }^{1}$ There are many low-quality coal deposits in the world. These deposits have coals with low liberalization grain sizes. For this reason, it is necessary to make them in fine sizes before enrichment. ${ }^{2}$ On the contrary, coal particles in the size of dust are wasted in all process stages of coal, although it is produced in large sizes.

Conventional methods are insufficient to separate ultra-fine grains from each other. New methods should be found to recover valuable minerals from wastes and to prevent some environmental problems. ${ }^{3}$ Flotation is one of the enrichment methods that can be applied to fine-grained coals. In this method, separation is performed depending on the surface properties of coal and inorganic components. ${ }^{4}$ Although flotation is the most common method used, it is not very effective for ultrafine particles. ${ }^{5}$ As an alternative to the flotation method; flocculation, oil agglomeration and hydrophobic flocculation methods are used for the enrichment of fine-grained coals.

Hydrophobic flocculation is one of the aggregation methods based on the flocculation of fine particles in aqueous suspension with the effect of hydrophobic interaction and mechanical stirring. It is separated from finegrained coal impurities depending on the differences of surface properties between organic and mineral matter. Medium-density oils such as non-polar kerosene and diesel are added to the suspension to increase the hydrophobicity of the grains. ${ }^{6}$ In addition, dispersants such as sodium silicate, sodium polystyrene sulfonate, tannic acid, sodium hexametaphosphate, sodium phosphate and sodium pyrophosphate are used to prevent non-hydrophobic particles from agglomeration with hydrophobic particles and to increase selectivity. ${ }^{7}$ The main purpose of these processes is to cover the hydrophobic grains with oil film in order to increase 
hydrophobicity and to keep the agglomerated grains together by forming a bridge between the particles. ${ }^{6,8}$ Many studies have been conducted on removing impurities from hydrophobic particles by hydrophobic flocculation. . $^{3,5,7,9-15}$

In this study, it was aimed to clean the fine-grained coal by using waste motor oil by hydrophobic flocculation. Hydrophobic flocculation behavior was investigated using different parameters during coal enrichment. Ash content, combustion recovery, contact angle, zeta potential and calorific value of the flocks were determined and interpreted in detail.

\section{Materials and Method}

\section{Materials}

In this study, lignite coal of Beyşehir (Bayavşar) Konya region was used. A sample of $100 \mathrm{~kg}$ brought to the laboratory. The coal sample was crushed to under size of $3.5 \mathrm{~cm}$ by jaw crusher. Then, the sample was ground at a ball mill Ø180x362 mm with an internal volume of $9 \mathrm{~L}$. After the size reduction process, the entire coal sample was sieved and $-212 \mu \mathrm{m}$ sized sample was obtained. The particle size distribution of the coal sample was determined and the $\mathrm{d}_{80}$ value, which is the sieve opening that through $80 \%$ of the grains passes, was determined as $75 \mu \mathrm{m}$. The sample was dried and analysed. Analysis results were given in Table 1.

Table 1. Proximate analysis of the coal sample.

\begin{tabular}{lcccc}
\hline Sample & $\begin{array}{c}\text { Ash, } \\
(\%)\end{array}$ & $\begin{array}{c}\text { Volatile Matter, } \\
(\mathbf{\%})\end{array}$ & $\begin{array}{c}\text { Fixed Carbon, } \\
(\boldsymbol{\%})\end{array}$ & $\begin{array}{c}\text { Upper Calorific } \\
\text { Value, }(\mathbf{k c a l} / \mathbf{k g})\end{array}$ \\
\hline Coal & 36.40 & 42.78 & 20.82 & 2529 \\
\hline
\end{tabular}


Calorific value of the coal sample was determined using LECO brand AC-350 adiabatic oxygen bomb calorimeter by ASTM D 5865-11a standard. ${ }^{16}$ Ash analysis was carried out in accordance with the standard (ASTM D 3174-04, 2010) ${ }^{17}$ using Gemo brand TT107 model ash furnace. Volatile matter determination was carried out using the standard test method $\left(\right.$ ASTM D3175-18) ${ }^{18}$. The remaining part from moisture, ash and volatile matter in the sample was calculated as the fixed carbon value. In the experiments, Merck brand sodium silicate (1\%) and Castrol CRB Turbomax 15/40 brand waste motor oil were used as dispersant and binder, respectively. Solution $\mathrm{pH}$ was adjusted with $\mathrm{HCl}(1 \%)$ and $\mathrm{NaOH}(5 \%)$.

\section{Method}

Hydrophobic flocculation experiments were carried out in a $400 \mathrm{~mL}$ beaker with 4 barriers. These barriers were placed on the inner surface of the beaker both to obtain a homogeneous mixture and to increase the collision efficiency of the grains. After flocculation, non-flocculated particles were removed by a special siphoning system placed in a beaker. The suspension prepared with $300 \mathrm{~mL}$ of distilled water and 5 grams of coal sample was mixed for 2 minutes at $1000 \mathrm{rpm}$. After adjusting the solution $\mathrm{pH}$ to the desired value, the dispersant was added and mixed for 2 minutes. Later, waste engine oil was added to the system and mixed for 2 minutes. At the end of this period, the stirring speed was reduced to $180 \mathrm{rpm}$ and flock growth was achieved. Experiments were carried out at different values of $\mathrm{pH}(3,5,7,9$ and 11), amount of dispersant (1, 1.5, 2 and $2.5 \mathrm{~mL})$, amount of binding liquid (1, 2, 3 and $4 \mathrm{~mL}$ ), flock growth times (1, 3, 5 and $7 \mathrm{~min}$ ), stirring speed (250, 500, 750, 1000 and $1250 \mathrm{rpm})$, flocculation time (1, 2, 3 and $4 \mathrm{~min})$ and solid ratio $(3,4,5$ and $6 \mathrm{~g})$. The schematic representation of the steps followed in the experiments was given in Figure 1. 


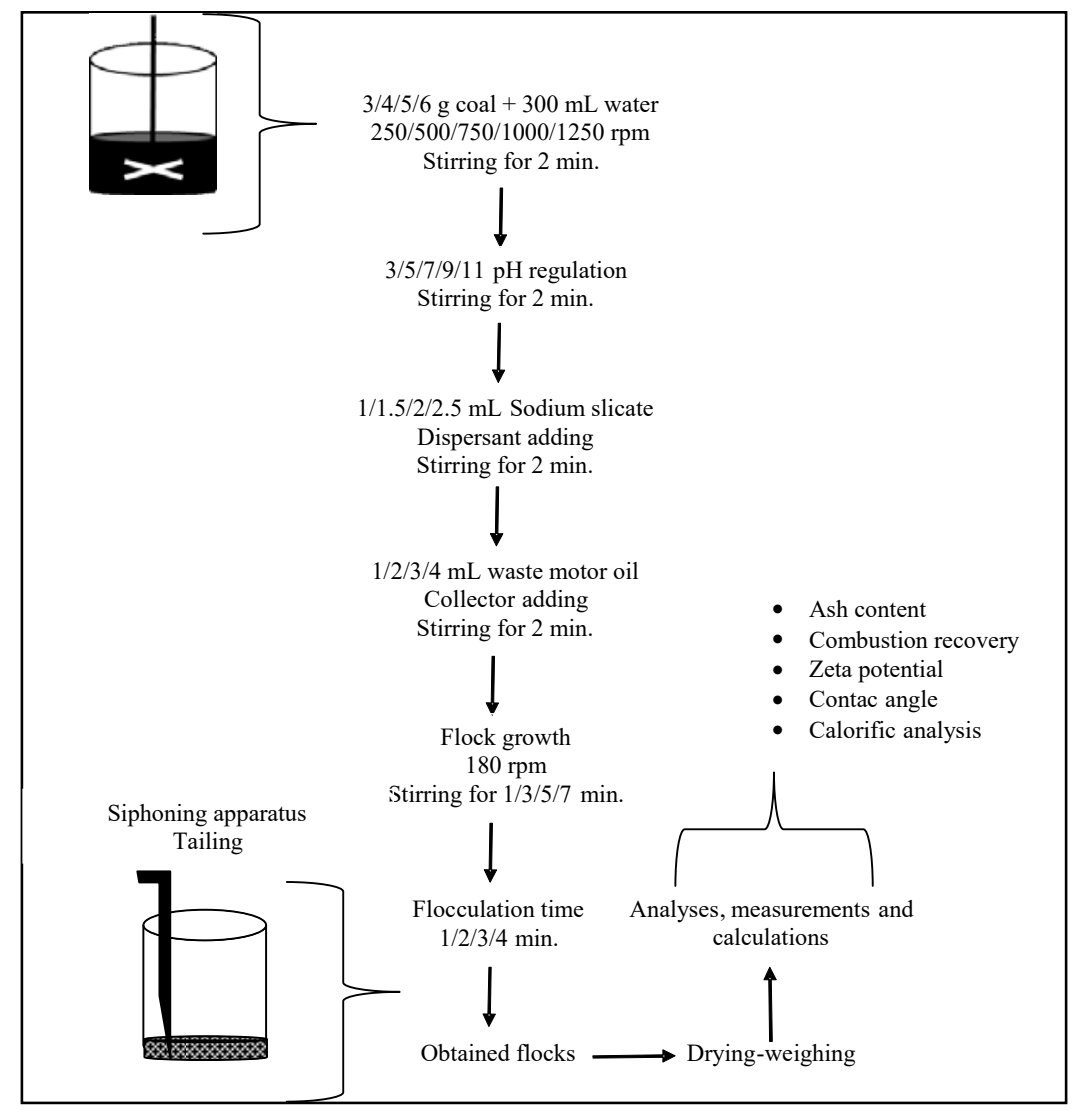

Figure 1. The flow diagram followed in the experiments.

The flocks formed after the experiments were collected on the upper part of the suspension. The other non-flocculated part was removed with a specially designed siphoning system. Flocks were filtered through the filter paper, dried at $105{ }^{\circ} \mathrm{C}$ for 4 hours and weighted. The flock recovery (FR\%) after flocculation was calculated by Eq. 1. The ash content of the hydrophobic flocks was determined and the combustion recovery $(\mathrm{CR} \%)$ of the flocks was calculated using Eq. 2. 


$$
\begin{aligned}
& F R, \%=\frac{W_{f}}{W_{f}} \cdot 100 \\
& C R, \%=\frac{F E\left(100-A_{f}\right)}{\left.100-A_{f}\right)}
\end{aligned}
$$

where $A_{c}$ is the ash content of clean coal, $A_{f}$ is the ash content of feed $W_{c}$ is weight of clean coal and $W_{f}$ is weight of feed.

Brookhaven Zeta Plus brand zeta meter (measurement range $-150-+150 \mathrm{mV}$, standard deviation $2 \mathrm{mV}$ ) was used for the zeta potential measurements. The zeta potential of the fine-grained coal sample and mixture of coal-waste motor oil sample were measured at natural $\mathrm{pH}$ and different $\mathrm{pH}$ values in suspension. Measurement results were given in Figure 2.

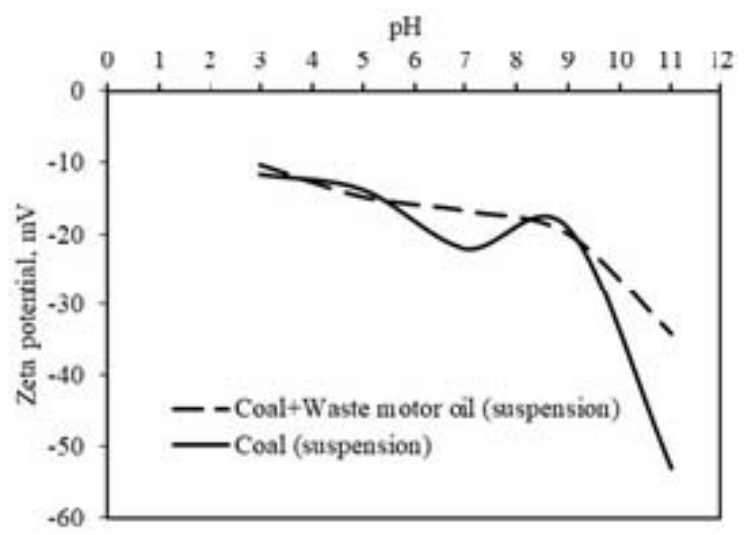

Figure 2. Zeta potential values of suspensions containing coal samples at different $\mathrm{pH}$ values.

The coal sample and flocks obtained after hydrophobic flocculation were placed in a specially prepared apparatus. Pellets were formed with the help of a hydraulic press under $20 \mathrm{kN}$ pressure. The static contact angles of these pellets, which were smooth on both surfaces, were measured with the KSV brand Cam 101 model contact angle measuring device (Figure 3). Each measurement was repeated four times and average values were calculated. 


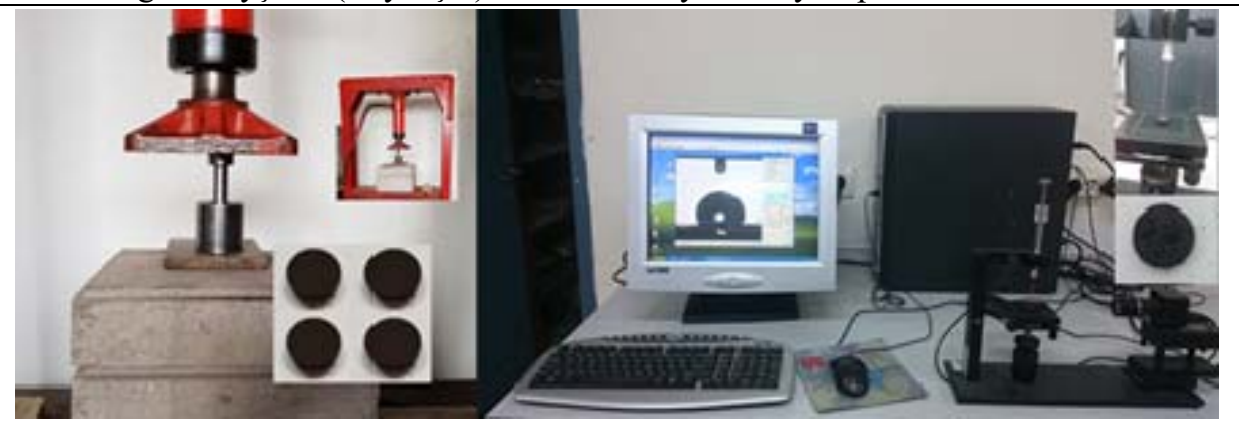

Figure 3. The creation of pellets and contact angle measurement.

\section{Results and Discussion}

The experiments at different $\mathrm{pH}$ values $(3,5,7,9$ and 11) were carried out to determine the effect of $\mathrm{pH}$ on hydrophobic flocculation of the fine-grained coal sample. The results obtained were given in Figure 4. Amount of sodium silicate, amount of waste motor oil, flock growth time, stirring speed, flocculation time and solid ratio were kept constant.

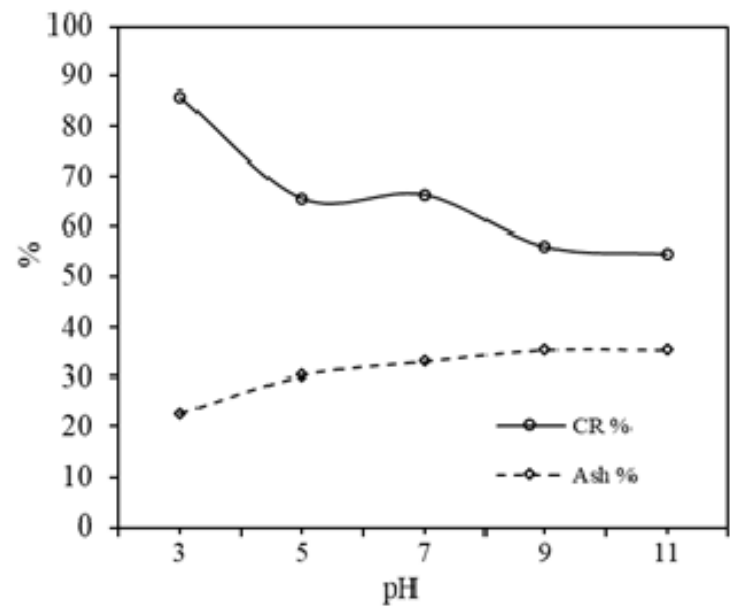

Figure 4. Variations of combustible recovery and ash percentage depending on $\mathrm{pH}$ ( sodium silicate $=1 \mathrm{~mL}$, waste motor oil $=1 \mathrm{~mL}$, stirring speed $=1000 \mathrm{rpm}$, flock growth time $=1 \mathrm{~min}$, flocculation time $=2 \mathrm{~min}$, solid ratio $=5 \mathrm{~g}$ ).

As seen in Figure 4, it was seen that the ash content of the hydrophobic flocks increased with increasing $\mathrm{pH}$. However, it was determined that the combustible recovery of the flocks was high at low $\mathrm{pH}$ 
values. The clean coal was obtained at $\mathrm{pH}=3$ with a combustible recovery of $85.92 \%$ and an ash content of $22.78 \%$. The zeta potential measurements of the particle surfaces in the suspension were evaluated depending on the $\mathrm{pH}$ values. According to the measurement results, it was determined that the zeta potential at $\mathrm{pH} 3$ was $-10.36 \mathrm{mV}$, the zeta potential at $\mathrm{pH} 11$ was $-34.21 \mathrm{mV}$ and at the neutral $\mathrm{pH}$ value was $-21.99 \mathrm{mV}$. Electrostatic interactions decrease and hydrophobic interaction between coal particles increases at low $\mathrm{pH}$ values. On the contrary, larger zeta potentials are measured in alkaline solutions and are known to increase the electrostatic repulsion between particles. ${ }^{19,20}$

To determine the effect of the amount of sodium silicate added as a dispersant in different values $(1,1.5,2,2.5 \mathrm{~mL})$ on the hydrophobic flocculation of the coal sample, experiments were carried out at $\mathrm{pH} 3$ by keeping other parameters constant. The results were given in Figure 5.

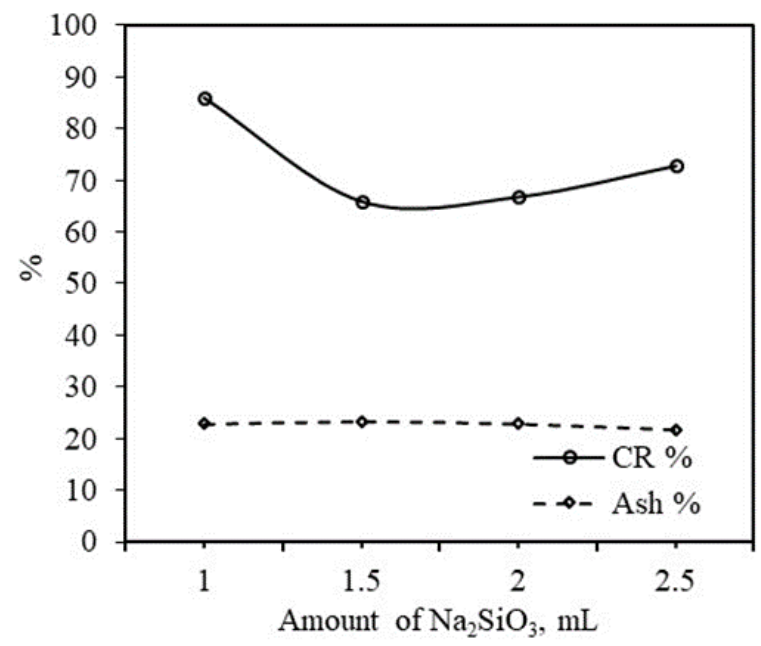

Figure 5. Variations of combustible recovery and ash percentage depending on the amount of sodium silicate $(\mathrm{pH}=3$, waste motor oil $=1 \mathrm{~mL}$, stirring speed $=1000 \mathrm{rpm}$, flock growth time $=1 \mathrm{~min}$, flocculation time $=2 \mathrm{~min}$, solid ratio $=5 \mathrm{~g}$ ).

As can be seen from Figure 5, in the hydrophobic flocculation experiments performed with waste motor oil, there was not much change in 
ash content with the increase of sodium silicate. The clean coal was obtained with $85.92 \%$ combustible recovery and $22.78 \%$ ash content using $1 \mathrm{~mL}$ sodium silicate. It is stated that dispersants such as sodium silicate, sodium polystyrene sulfonate, tannic acid, sodium hexametaphosphate, sodium phosphate and sodium pyrophosphate are used in hydrophobic flocculation processes to increase the selectivity of non-hydrophobic particles. ${ }^{7}$ It is known in the literature that Ermenek coals have similar properties in hydrophobic flocculation with the addition of sodium silicate. ${ }^{3}$ In addition, it was determined that sodium silicate had no negative effect on hydrophobic flocculation experiments. ${ }^{3,15}$

The results of hydrophobic flocculation performed with waste motor oil used in different amounts $(1,2,3.4 \mathrm{~mL})$ were given in Figure 6.

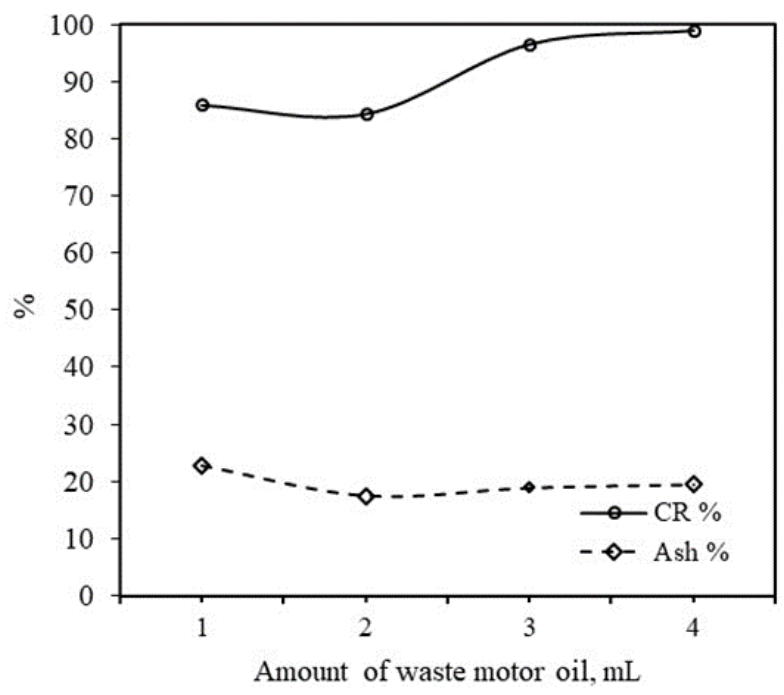

Figure 6. Variations of combustible recovery and ash percentage depending on the amount of waste motor oil $(\mathrm{pH}=3$, sodium silicate $=1 \mathrm{~mL}$, stirring speed $=1000 \mathrm{rpm}$, flock growth time $=1$ min, flocculation time $=2 \mathrm{~min}$, solid ratio $=5 \mathrm{~g}$ ).

With the increase in the amount of oil, the ash content decreased while the CR value increased. However, it was found that the ash content increased after a certain amount with the increase in the amount of oil. It is 
known that the amount of oil creates unstable flocks after a certain value.

The unstable nature of the flocks ensures rapid dispersion. ${ }^{21}$ Also, it is easier for mineral substances to enter between the flocks. ${ }^{22}$ The clean coal was obtained with $96.45 \%$ combustible recovery and $18.15 \%$ ash content using $3 \mathrm{~mL}$ waste motor oil.

In Figure 7, the effect of the flock growth time on the hydrophobic flocculation test results was examined. The stirring speed was reduced to $180 \mathrm{rpm}$ and the flocks were grown at different times (1, 3, 5, $7 \mathrm{~min})$. As can be seen from Figure 7, it is seen that the CR values decrease with the increase of the flock time and the ash values increase even if a little. Therefore, flock growth time was taken as $1 \mathrm{~min}$.

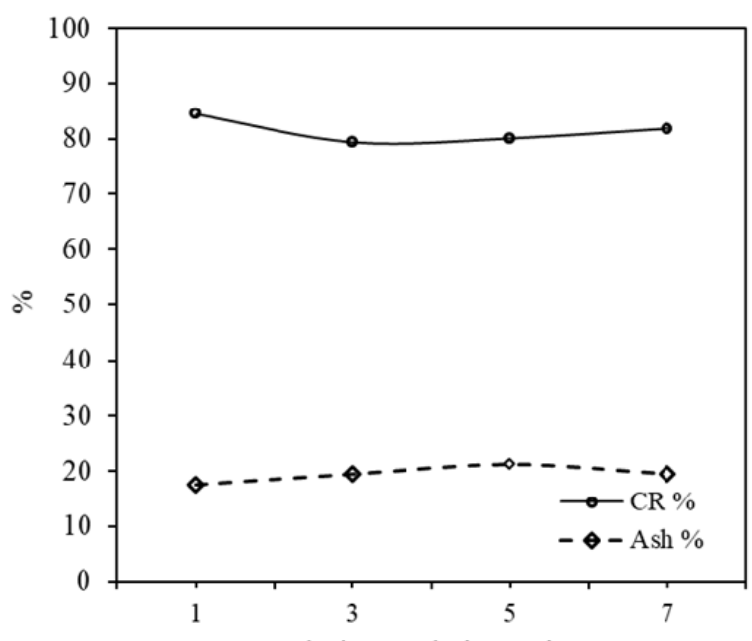

Flock growth time, min.

Figure 7. Variations of combustible recovery and ash percentage depending on flock growth time $(\mathrm{pH}=3$, waste motor oil $=1 \mathrm{~mL}$, sodium silicate $=1 \mathrm{~mL}$, stirring speed $=1000 \mathrm{rpm}$, flocculation time $=2 \mathrm{~min}$, solid ratio $=5 \mathrm{~g}$ ).

In order to investigate the effect of stirring speed on hydrophobic coal flocculation, experiments were conducted at different stirring speeds (250, 500, 750, 1000 and $1250 \mathrm{rpm})$. As can be seen from Figure 8, ash contents decrease with high CR with increasing stirring speed. For this reason, the optimum stirring speed of $1250 \mathrm{rpm}$ was determined. Flocks 

were obtained with an ash content and combustion recovery, $17.03 \%$ and 99.06\%, respectively. According to Sahinoglu and Uslu (2008), ${ }^{21}$ oils provide better dispersion in suspension with increasing stirring speed and the possibility of particle collision with each other increases. In the literature, it is stated that the flocculation and aggregation effect increases with the increase of the stirring speed and decreases after the critical value. ${ }^{23,24}$ On the contrary, it is thought that the decrease in the stirring speed accelerates the entry of ash-forming inorganic materials into the agglomerated coal grains. For these reason, it can be said that ash content (\%) has increased. ${ }^{3,21,25-27}$

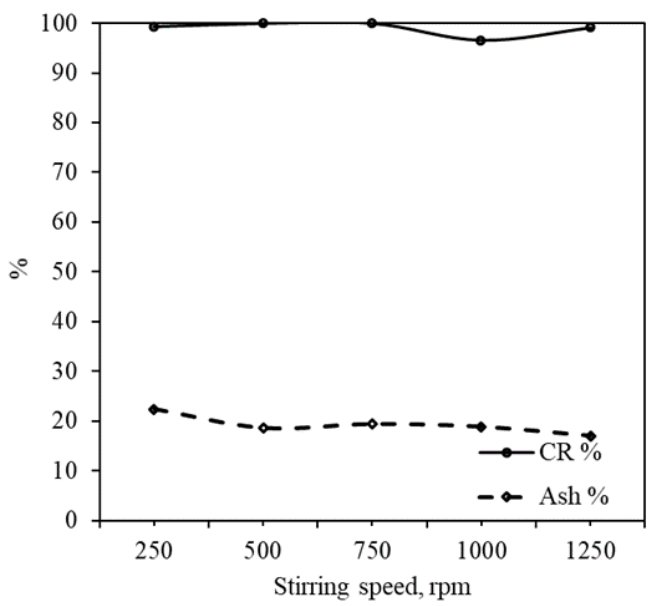

Figure 8. Variations of combustible recovery and ash percentage depending on stirring speed $(\mathrm{pH}=3$, waste motor oil $=1 \mathrm{~mL}$, sodium silicate $=1 \mathrm{~mL}$, flock growth time $=1 \mathrm{~min}$, flocculation time $=2 \mathrm{~min}$, solid ratio $=5 \mathrm{~g}$ ).

In Figure 9, the effect of different flocculation time (1, 2, 3, 4 min) on hydrophobic flocculation of coal was examined. The flocculation time was determined as $2 \mathrm{~min}$. The clean coal was obtained with $99.06 \%$ combustible recovery and $17.03 \%$ ash content. As time increased, there was an increase in very little ash content and a decrease in CR values. A similar situation was mentioned in the literature. ${ }^{28}$ With the increase in the flocculation time, the particles were brought together with the oil. However, 
as the time increased, it was seen that the mineral grains entered the flocks. $^{29}$

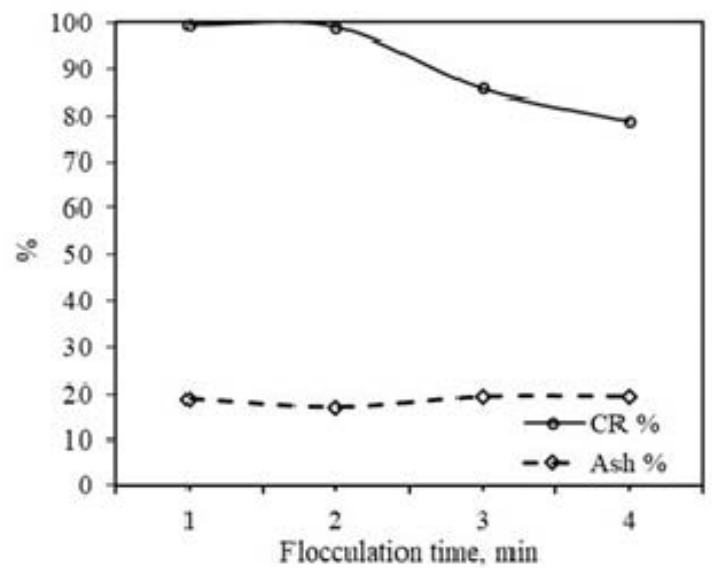

Figure 9. Variations of combustible recovery and ash percentage depending on flocculation time $(\mathrm{pH}=3$, waste motor oil $=1 \mathrm{~mL}$, sodium silicate $=1 \mathrm{~mL}$, stirring speed $=1250 \mathrm{rpm}$ flock growth time $=1 \mathrm{~min}$, solid ratio $=5 \mathrm{~g}$ ).

As seen in Figure 10, the effect of solid ratio on hydrophobic flocculation was examined. According to the experimental results, optimum results were obtained by using $5 \mathrm{~g}$ of coal in the suspension. Although CR values were high in all solid ratios, the lowest ash content $(17.03 \%)$ was obtained by using $5 \mathrm{~g}$.

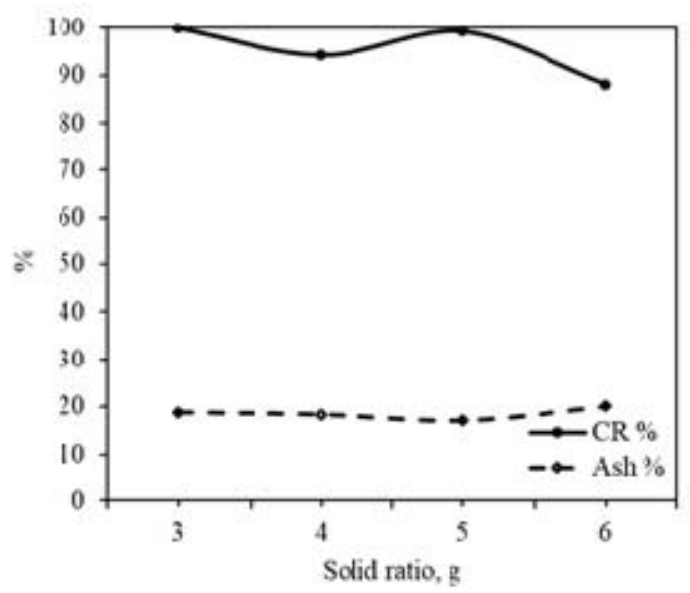

Figure 10. Variations of combustible recovery and ash percentage depending on solid ratio $(\mathrm{pH}=3$, waste motor oil $=1 \mathrm{~mL}$, sodium silicate $=1 \mathrm{~mL}$, stirring speed $=1250 \mathrm{rpm}$, flock growth time $=1 \mathrm{~min}$, flocculation time $=2 \mathrm{~min}$ ). 
Contact angle measurements, indicative of its hydrophobicity, were carried out by the KSV brand Cam 101 model contact angle measuring device. While the contact angle of the original coal was $44^{\circ}$, the contact angle of the obtained flocks was measured as $117^{\circ}$ (Figure 11).

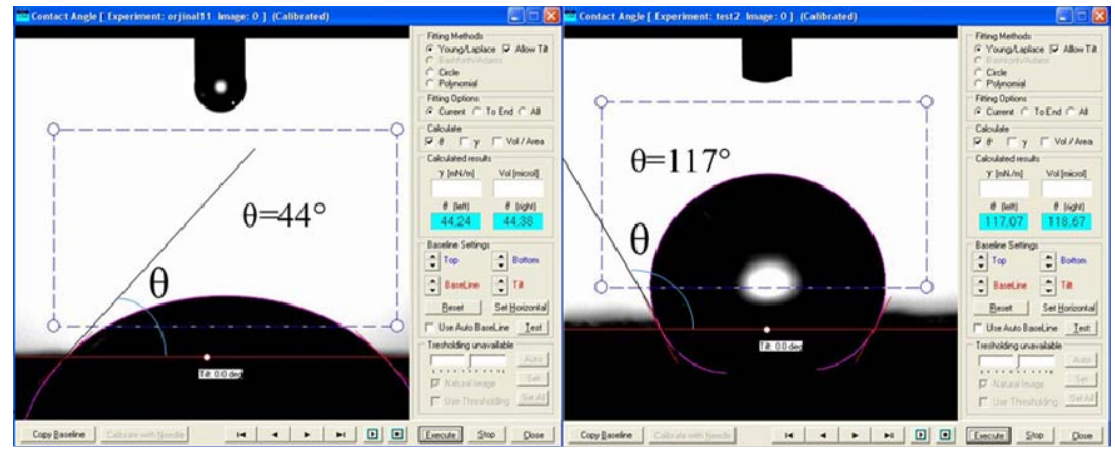

Figure 11. Contact angle measurement results.

This result confirms that the flocked surfaces obtained are highly hydrophobic. Measuring the zeta potential value of $-10.93 \mathrm{mV}$ also supports these results. In addition, the calorific values of the obtained flocks were measured. The coal sample's calorific value was increased from $2529 \mathrm{kcal} / \mathrm{kg}$ to $5447 \mathrm{kcal} / \mathrm{kg}$.

\section{Conclusions}

Hydrophobic flocculation experiments were carried out using Beyşehir coal sample. In addition, waste motor oil was used as a binder liquid in the experiments to obtain clean coal. The effects of $\mathrm{pH}$, dispersant $\left(\mathrm{Na}_{2} \mathrm{SiO}_{3}\right)$ amount, binder liquid (waste motor oil) amount, flock growth time, stirring speed, flocculation time and solid ratio on hydrophobic flocculation behavior of coal sample were studied in detail. The optimum operating parameters for hydrophobic flocculation were determined as follows: $\mathrm{pH}=3, \mathrm{Na}_{2} \mathrm{SiO}_{3}$ amount $(1 \mathrm{~mL})$, waste motor oil amount $(3 \mathrm{~mL})$, flock growth time $(1 \mathrm{~min})$, stirring speed $(1250 \mathrm{rpm})$, flocculation time 
( $2 \mathrm{~min}$ ) and solid ratio (5 g). According to the optimum results, hydrophobic flocs with $17.03 \%$ ash content and $90.06 \%$ combustible recovery were obtained. The calorific value of the coal sample, which was $2529 \mathrm{kcal} / \mathrm{kg}$, was increased to $5447 \mathrm{kcal} / \mathrm{kg}$.

\section{References}

1. Osborne, D. G.; Gupta, S. K. Industrial uses of coal. In The coal handbook: Towards cleaner production (Volume 1: Coal production); D. G. Osborne, Ed.; Woodhead Publishing Limited, 2013, pp 3-30.

2. Vince, A. Post-treatment of coal. In The coal handbook: Towards cleaner production (Volume 1: Coal production); D. G. Osborne, Ed.; Woodhead Publishing Limited, 2013, pp 467-528.

3. Duzyol, S. Investigation of oil agglomeration behaviour of Tuncbilek clean coal and separation of artificial mixture of coal-clay by oil agglomeration. Powder Technol. 2015, 274, 1-4.

4. Aktas, Z. Some factors affecting spherical oil agglomeration performance of coal fines. Int. J. Miner. Process. 2002, 65, 177-190.

5. Song, S.; Lopez-Valdivieso, A. Hydrophobic flocculation flotation for beneficiating fine coal and minerals. Sep. Sci. Technol. 1998, 33, 1195-1212.

6. Mazzone, D. N.; Tardos, G. I.; Pfeffer, R. The effect of gravity on the shape and 770 strength of a liquid bridge between two spheres. $J$. Colloid Interface Sci. 1986, 113, 544-556.

7. Duzyol, S.; Sensogut, C. The relation between hydrophobic flocculation and combustion characteristics of coal. Fuel Process. Technol. 2015, 137, 333-338.

8. Song, S.; Lopez-Valdivieso, A.; Ding, S. Effects of nonpolar oil on hydrophobic flocculation of hematite and rhodochrosite fines. Powder Technol. 1999, 101, 73-80.

9. $\mathrm{Xu}, \mathrm{Z}$; Y Yoon, R. The role of hydrophobic interactions in coagulation. $J$. Colloid Interface Sci. 1989, 132, 532-541.

10. Warren, L. J., Colloid chemistry in mineral processing. In J. S. Laskowski, J. Ralston (Eds.).; Elsevier, Amsterdam. 1992, pp. 309-329. 
11. Skvarla, J. On the decay of polar surface forces between hydrophobic surfaces and colloids: 1. Coagulation. J. Colloid Interface Sci. 1993, 155, 506-508.

12. Song, S.; Trass, O. Floc flotation of Prince coal with simultaneous grinding and hydrophobic flocculation in a Szego mill. Fuel. 1997, 76, 839-844.

13. Yu, Z. Flocculation, hydrophobic agglomeration and filtration of ultrafine coal. ( $\mathrm{PhD}$ thesis), The University of British Columbia, 1998, p. 246.

14. Song, S.; Lopez-Valdivieso, A.; Reyes-Bahena, J. L.; Bermejo-Perez, H. I. Hydrophobic flocculation of sphalerite fines in aqueous suspensions induced by ethyl and amyl xanthates. Colloids Surf, A Physicochem. Eng. Asp. 2001, 181, 159-169.

15. Ucbeyiay, H. Hydrophobic flocculation and Box-Wilson experimental design for beneficiating fine coal. Fuel Processing Technology. 2013, 106, 1-8.

16. ASTM D 5865-11a. Standard test method for gross calorific value of coal and coke from coal. 2011, 14.

17. ASTM D 3174-04. Standard test method for ash in the analysis sample of coal and coke from coal. 2010, 5.

18. ASTM D 3175. Standard test method for volatile matter in the analysis sample of coal and coke from coal. 2018, 5.

19. Ozdemir, O.; Taran, E.; Hampton, M. A.; Karakashev, S. I. Nguyen, A.V. Surface chemistry aspects of coal flotation in bore water. Int. J. Miner. Process. 2009, 92, 177-183.

20. Duzyol, S.; Sensogut, C. Aksu, A. O.; Erisir, H. S.; Aspir, K. Benefication of Tuncbilek lignites by oil agglomeration. In M.E. Bilir, K. Kel, E. Kaymakci (Eds.). Proceedings of the 19th Coal Congress of Turkey, Zonguldak/Turkey. 2014, pp. 237-244.

21. Sahinoglu, E.; Uslu, T. Amenability of Muzret Bituminous Coal to oil agglomeration. Energy Convers. Manag. 2008, 49, 3684-3690.

22. Yasar, O. Tunçbilek lavarı ince atıklarından yă̆ aglomerasyonu yöntemiyle kömür kazanımı. ( $\mathrm{PhD}$ thesis), Karadeniz Technical University, Trabzon, 2018. 
23. Cebeci, Y.; Sonmez, I. Application of the Box-Wilson experimental design method for the spherical oil agglomeration of coal. Fuel 2006, 85, 289-297.

24. Arslan, N.; Unal, I. Multi-response optimization of oil agglomeration with multiple performance characteristics. Fuel Process. Technol. 2011, 92 (6), 1157-1163.

25. Chary, G. H. V. C.; Dastidar, M. Optimization of experimental conditions for recovery of coking coal fines by oil agglomeration technique. Fuel 2010, 89, 2317-2322.

26. Duzyol, S. Investigation of oil agglomeration behaviour of Karadon (Zonguldak) coal using Taguchi experimental design. C.U. Journal of the Faculty of Engineering and Architecture 2016, 31(2), 77-84.

27. Agacayak, T.; Duzyol, S. Optimization of oil agglomeration behaviour of coal by Taguchi design. J. Int. Sci. Publ.: Mater. Methods Technol. 2018, 12, 179-186.

28. Arı, M. Farklı bağlayıcı sıvı karışımları ile kömürün yă̆ aglomerasyonuyla zenginleştirilmesi. (MSc thesis), Cumhuriyet University, Sivas. 2017, p.99.

29. Shukla, D.; Venugopal, R. Optimization of the process parameters for fine coal-oil agglomeration process using waste mustard oil. Powder Technol. 2019, 346, 316-325. 